\title{
The importance of ergonomics in the design conceptual process: Daciano da Costa- A case study on practicing and teaching
}

\author{
Ana Moreira da Silva ${ }^{a}$ \\ ${ }^{a}$ CIAUD, Faculty of Architecture, Technical University of Lisbon, Portugal \\ Rua Sá Nogueira, Pólo Universitário, Alto da Ajuda, 1349-055 Lisboa, Portugal \\ E-mail: anamoreiradasilva@gmail.com
}

\begin{abstract}
This paper, which stems from a developing research project, aims to disseminate among the international scientific community the thought of Daciano da Costa (1930-2005) given the importance he conferred to Ergonomics, throughout his teaching career and his professional practice as a reference figure in the Design of the twentieth century in Portugal. We focus on the important role played by Ergonomics within the conceptual Design process, through the case study Daciano da Costa. What Daciano brought to the practice and teaching was a modernization of processes, a new perspective on the emerging themes of design, like ergonomics. Daciano believed that designing was providing a service. This task was understood as the building of a relationship with users. One of his distinguished features was the particular attention he paid to the unique aspects of the scale of proximity: the scale of the hand, of the immediate gesture, of the body. As a professor he insisted not so much on the end product, but rather on the recognition of the research process and how it was conducted. When designing, developing and supervising the exercises he set, ergonomic factors were one of his main concerns.
\end{abstract}

Keywords: Design, Ergonomics, Daciano da Costa, Design Conceptual Process, Teaching

\section{Introduction}

We cannot speak about Portuguese Design without referring to Daciano da Costa.

He was one of the pioneers of industrial design in Portugal. For more then four decades he conceived furniture and other product design, still used satisfactory nowadays.

He has played a pioneer role on Design's theory fundaments in Portugal and an important pedagogic role as a teacher.

Daciano created and implemented the Design Course Plan, established in 1991 at the FA/UTL, Technical University of Lisbon, being is coordinator since then until 2003.

Daciano's teaching method was remarkably operational, within a wider understanding of ergonomics and how to apply it and the recognition of what the

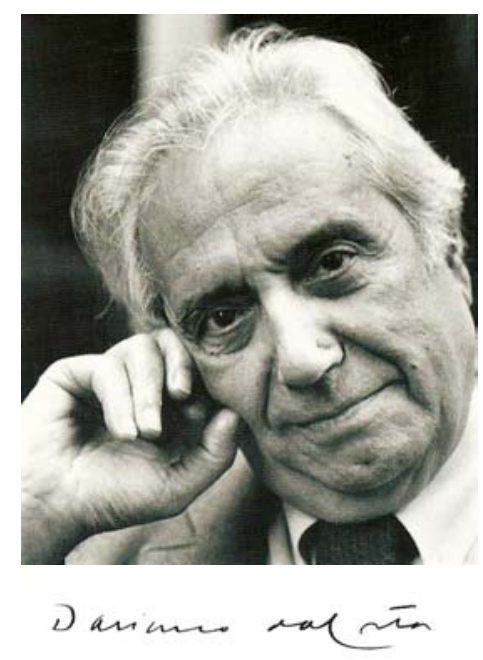

Figure 1 - Daciano da Costa (1930-2005) subject can do. [4] 


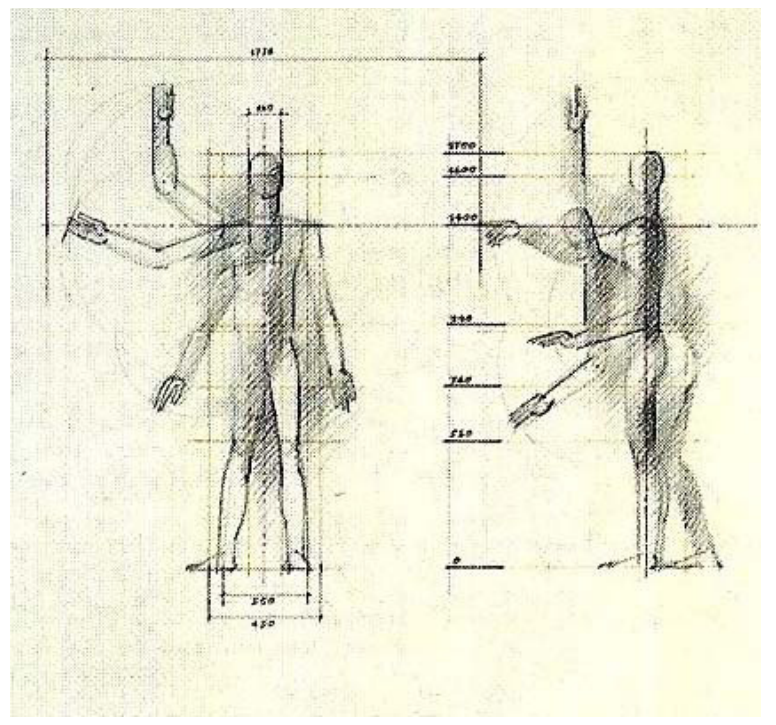

Figure 2 - Daciano's matrix of ergonomic studies for working furniture (1971)

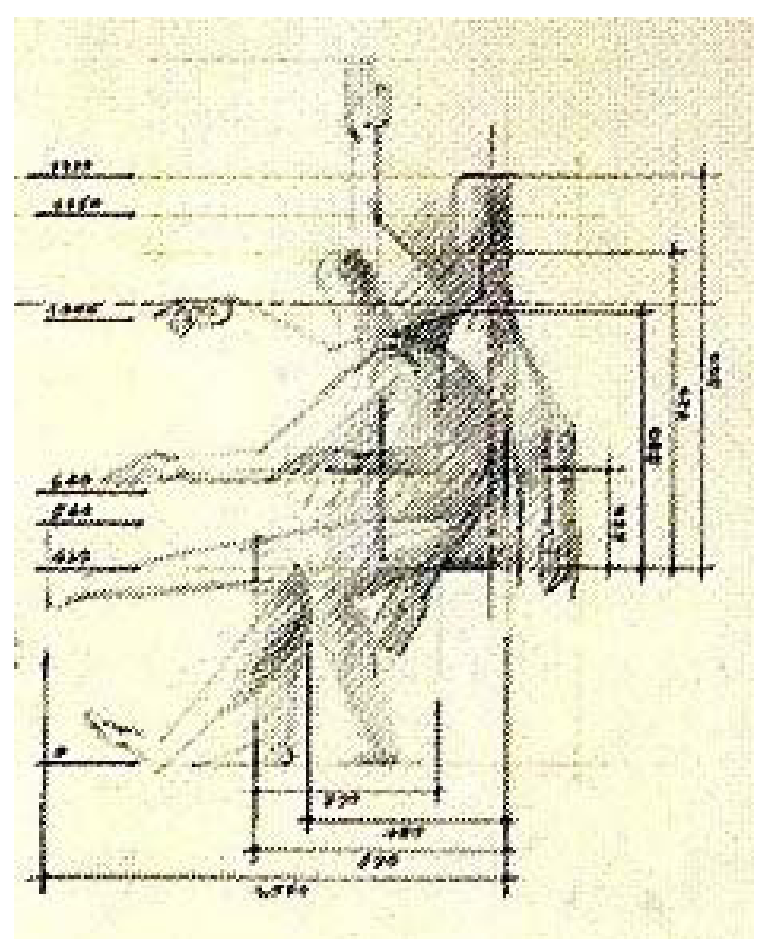

Figure 3 - Other Daciano's sketch of ergonomic studies (1971)

Daciano da Costa stated that Man is the real protagonist of space [1]. He was concerned with the design of systems in which people carry out work.

According to Cushman \& Rosenberg [2] product design is the process of creating newest and better products for people to use. Ergonomics is responsible for the product usability focusing in the comfort, efficiency and safety.

In the design for everyday life situations, the focus of ergonomics is man.

For Daciano [1], ergonomics contributes to the design and evaluation of work systems and products.

As Oborne [5] outlines a major role of ergonomics is to identify design issues which involve the human component of the work system.

To exemplify those issues in Daciano da Costa's work we present the figures 1-5 with his sketches [3] that represent a clear and direct demonstration of the importance he conferred to ergonomics in the design conceptual process, since the first ideas untill the evaluation and implementation of the several solutions.

A direct relationship between the human figure and the sketches for different kinds of furniture and other types of equipment, is always present along the several stages of his design conceptual process.

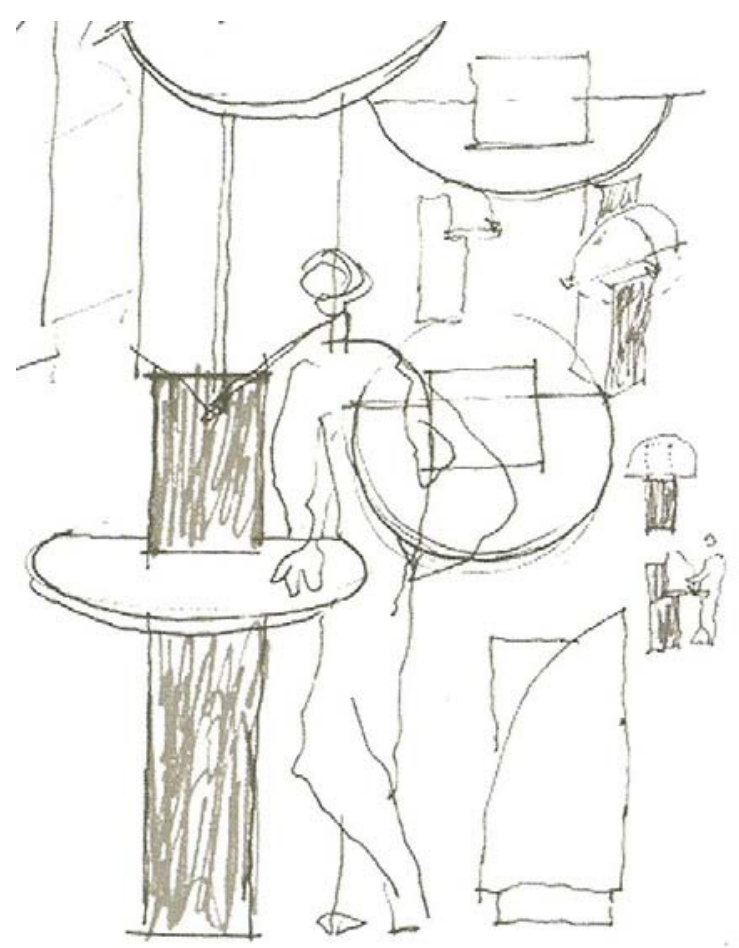

Figure 4. Daciano da Costa. Furniture line Metropolis. Sketches (1988) 


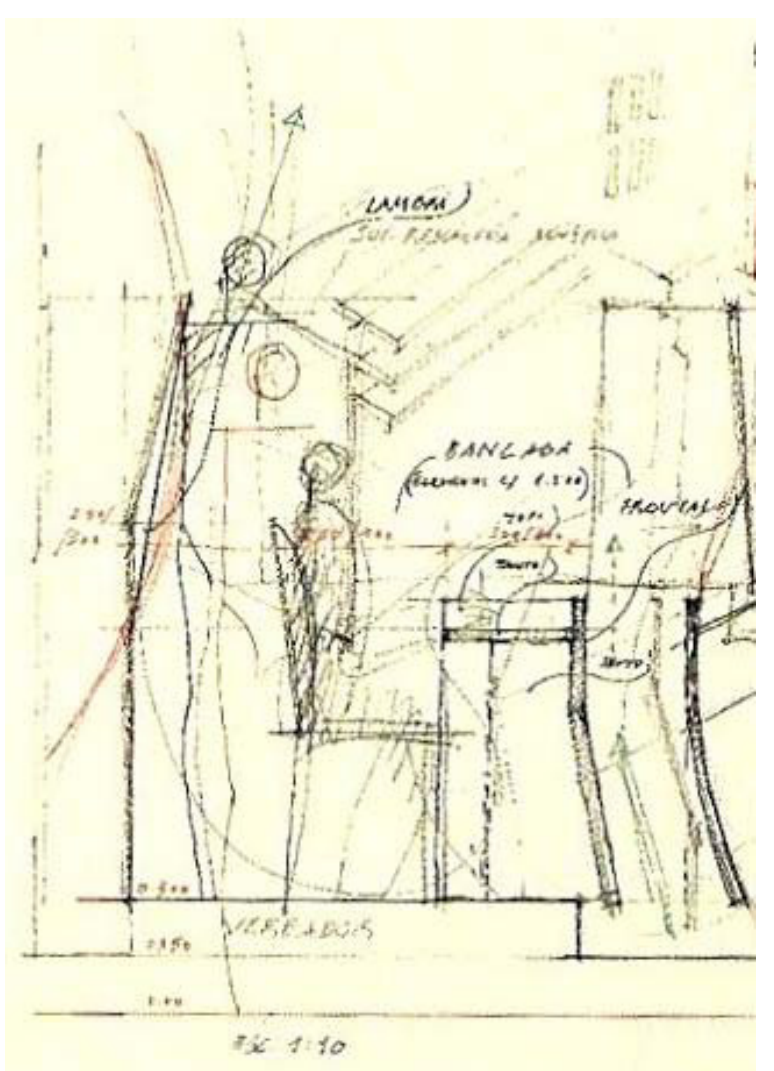

Figure 5 - Lisbon City Council Buildings. Councillors' bench. Sketches. Daciano da Costa (1997)

\section{References}

[1] Costa, D., Design e Mal-Estar, Centro Português de Design, Lisboa, 1998, p. 26.

[2] Cushman, W. H., Rosenberg, D., Human Factors in Product Design. Elsevier, New York, 1991.

[3] Daciano da Costa Designer, Catálogo da Exposição na Fundação Calouste Gulbenkian, Lisboa, 2001, pp. 24, 78, 194 ,

[4] Guia das Licenciaturas 1993-1994, FA/UTL, Lisboa, 1993, p. 124.

[5] Oborne, D. J, Ergonomics at Work - Human Factors in Design and Development, John Wiley \& Sons, New York, 1998. 